Stajka Rajić, Ph. D. student

Accepted: $16^{\text {th }}$ January 2020

University of Belgrade

rajiccaca@gmail.com

Vesna Todorčević, Ph. D., Full Professor

University of Belgrade

vesna.torodrcevic@fon.bg.ac.rs

Alma Tasevska, Ph. D., Associate Professor

Saints Cyril and Methodius University of Skopje

alma@fzf.ukim.edu.mk

\title{
MATHEMATICS AND MUSIC GAME IN THE FUNCTION OF CHILD'S SOCIAL AND EMOTIONAL DEVELOPMENT
}

\begin{abstract}
The paper presents empirical research, aiming to present the extent to which the application of the concrete mathematical and musical play contributes to the child's social and emotional development. The research was conducted in two international schools in Belgrade, using the play titled 'Musical Monkeys' and in collaboration with the Music-Math team from Mexico who are the creators of the mentioned game. The results have shown that this kind of approach in working with children encourages activity and engagement, self-confidence, empathy, team work, integrity, tolerance and enthusiasm, while requiring and encouraging collaboration and constructive communication, cooperation and respect among students in the process of solving a set of mathematical and/ or musical tasks. The obtained results confirm that the children established connection between the mathematical and musical segments involving a high level of emotional and social skills - collaboration, communication, empathy, enthusiasm, commitment, curiosity for the game and felt benefits of team work, tolerance and respect while solving the given educational tasks.
\end{abstract}

Keywords: emotional skills, educational game activities, mathematics, music, social skills

\section{INTRODUCTION}

Learning through play is a natural part of a child's development. The game, as a fundamental component of child development and learning, has gained a 
prominent place in the modern world of education, learning and teaching. The game contributes to spontaneous learning, interactivity and dynamics through learning, as well as to the functional adoption of the learning content. Moreover, children's play encourages the development of their cognitive, social and emotional skills. In this paper we will depict how a specific math and music game influences child's social and emotional development.

Linking mathematical and musical content and organizing it into a didactical game the Music Math team from Mexico created a pedagogical, psychological, functional, educational, creative, dynamic and interactive game Musical Monkeys, which was the main part of the empirical research done and presented in this work. The first part of the work illustrates basic characteristics of the game as a powerful tool for children learning and development. Furthermore, paper describes characteristics of the didactical play and how it can be usefully and functionally used in the process of education. The second part is about the connection between math and music, and describes how that connection influences child development. This part is also an introduction to empirical research and presentation of the research results. The research was conducted in order to indicate the extent to which a new didactic mathematical-music play contributes to development of children's social and emotional skills.

\section{GAMES AS BASIS FOR CHILD'S DEVELOPMENT}

Psychologists have been researching and theorising about the play and its role in the development for well over a century. According to Trebješanin "...the game is a multifaceted term that includes different and opposite concepts" (Trebješanin, 2008:183). On the one hand, the game can be talked about as a free, spontaneous activity, which does not have a practical goal, but is performed for satisfaction. "The performance of a game is accompanied by feelings of joy and satisfaction. In addition to spontaneous games, the other group of games is organized, pre-planned, target-oriented activity, which has its clear rules, a certain start, flow and completion, such as various social, competitive and sports games" (Trebješanin, 2008:183). Trebješanin lists the following types of games: functional, language, dramatic, creative games, imagination games, games with rules, symbolic games, competitive and cooperative games, children's games and adult games, sports games, social games and others. Trebješanin also suggests that none of the many theories of children's games fail to fully encompass the classification of the game, as very complex and diverse activities (Trebješanin, 2008). In our research we have implemented a new interdisciplinary game that connects mathematics and music in order to encourage development of child social and emotional skills.

Kamenov states that "...the phenomenon of the game cannot be covered by a single definition" (Bruner et. al., 1976:13 according to Kamenov, 2009:7). In the interpretation and the definition of the concept of the game, different starting points 
are standing out - sociological, anthropological, pedagogical, medical, ecological, cultural, developmental and other (Kamenov, 2009; Tasevska, 2005; Whitebread, 2012).

Lev Vygotsky claims that children games make two crucial contributions to children's developing abilities, which relate to their development of language (and other human forms of symbolic representation) and to their developing abilities to control their own cognitive and emotional processes (Whitebread, 2012). According to him, the game has two functions for child development: the development of cognitive abilities and the development of will. In the game, a child creates an imaginary situation, which separates him from reality and thus highly contributes to the development of abstract thinking (Kamenov, 2009). Vygotsky argued that play is a crucial contribution to the development of the unique human attitude for using various forms of symbolic representation, whereby various kinds of symbols carry specific, culturally defined meanings (Whitebread, 2012).

"Games develop child's imagination as a valuable inner resource which can be used to foster creative thinking" (Plummer, 2008:13). In addition to influencing the development of cognitive abilities, many authors point out that children game contribute to their social and emotional development as well (Levy, 1978; Plummer, 2008; Whitebread, 2012). Children games provide invaluable opportunities for them to learn through imitation, to experience the consequences of their actions and to experiment with different skills and different outcomes without fear (Plummer, 2008).

\section{DIGITAL GAMES}

In the scientific literature games are usually represented as specific ways in educating children and youth. Didactic game requires intellectual activities and contributes to intellectual development of the child. These types of games are used for the purpose of education and learning (Dejic and Egeric, 2006). In education, it is increasingly emphasized that content cannot be learned by fear of authority or punishment. In order to make the children master educational content successfully, it is necessary to instigate their interests, enthusiasm and curiosity by creating functional, educational and didactic games (Pickering, 1871:29-30 according to Kamenov, 2009). Kamenov points to the educational and motivational value of children's games and the importance of the game in the socio-emotional development of the child. When discussing about educational aspect of the game, he argues that the value of the game is that the game keeps children's attention to certain content, while at the same time motivating them to be active participants in different educational activities (Kamenov, 2009). The game contributes to the stimulation and the development of perceptual-motor, intellectual, socio-emotional, communication and creativity skills (Vygotsky, 1996 according to Kamenov, 2009). Research on the phenomenon of the game indicates its importance of 
encouraging the intrinsic motivation of the child, strengthening self-control as well as directing child's attention to a certain activity, and encouraging affirmative forms of behaviour (Levy, 1978). Connecting mathematical and musical contents and then shaping them into a didactic play is the guiding idea of the research presented in our article with the general aim of showing how the math-music games could influence children social and emotional development.

While playing a game, children explore the world around them; they find new ways and opportunities to act in different situations, which are usually, associated with everyday children's life experiences. The game encourages children to be ready to adapt to change at any time, to use different sources of information, to explore and experiment in order to find more possible solutions to solve the same problem (Barr, 2017). Organized children's play, didactically and methodically conceived, provides the possibility of maximum children engagement in various learning activities. At the same time, the game contributes to the acquisition of new experiences, in relation to the environment and peers, as well as exercising and developing children's abilities. Children's interest in learning content is increasing, they are more satisfied and they progress in their development (Ivic, 1997).

\section{THE PEDAGOGICAL AND PSYCHOLOGICAL ASPECTS OF MATHEMATICS AND MUSIC IN THE FUCTION OF CHILD COGNITIVE DEVELOPMENT}

The term musical ability represents a central point between musical potential and musical achievement (Farnsworth, 1969 according to Rados, 2010). In her book Psychology of Music, she points out the most important components of musical abilities: distinguishing the tone height, observing and memorizing the melody, perceiving and reproducing rhythms, observing harmony, the ability to esthetical evaluate the music, observing tonality etc. (Rados, 2010).

When it comes to mathematical skills, the authors (Dejic and Egeric, 2006) emphasize that it is necessary to distinguish schools, for which natural preferences to mathematics and mathematical-logical thinking are not required, from scientific skills, in the basis of which lies the natural ability for deductive and inductive thinking, for using mathematical symbols, for logical conclusions, finding different and original solutions to given mathematical problems, setting new problems, performing the evidence, the ability to understand the causes and consequences, reasoning about relationships among objects (Dejic and Egeric, 2006). The stress is also on the division into algorithmic, geometric and logical mathematical skills, as well as on the skills to calculate, to solve complex mathematical tasks, use algorithms and use of measurements in mathematical questions (Denmark, 1980).

In general terms, both mathematics and music include the ability to perceive, remember, perceive connections between given relationships (in mathematics, or music) and creativity of thinking; both in mathematics and music there is 
a difference between learned skills and skills that are given by nature or talent (Dejic and Egeric, 2006; Rados, 2010). In the conducted pedagogical research and applied mathematical-music game for children aged from eight to twelve, emphasis was put on arithmetic and geometric contents of math; on the other hand in content of music it was rhythm, rhythmic pulse and musical perception.

For this purpose, it is important to point out that observing the rhythm stimulates a child's memory, remembering, observing rhythmic parts, observing accentuation of rhythmic strokes, meters, tempo while at the same time contribute to the development of children's rhythmic abilities (Rados, 2010). Mathematical games increase the development of self-control, true reasoning, effective and adequate intellectual response (Karić, 2015). Teaching mathematics using effective didactic strategies with the goal to develop students' conceptual understanding through the use of problem-solving activities, simulations, discoveries, and games, has the potential to reduce mathematical anxiety of some students (Song et. al, 2013).

Musical games supports a wide range of children's developing abilities, including those related to social interaction, communication, emotion understanding, memory, self-regulation and creativity (Whitebread, 2012). Children playing games constitute a potentially powerful educational tool because when students are given the freedom to explore the how and why; learning, understanding, and retention of different content naturally fall into place in the child's mind (Athey and Hotchkiss, 1978).

While implementing the math-music game Musical Monkeys as a new educational tool, we observed that game was exceptionally valuable and functional when working with children because the educational content is organized differently in a way that children enjoyed the learning procedure. Observing this process, we noticed that the connection between mathematics and music through the didactic math-music game give outcomes in child development that are significantly stronger from the outcomes obtained through single discipline games.

\section{RESEARCH RESULTS}

The math music game Musical Monkeys consists of two parts, one mathematical, where students use different didactic materials (coins and mathematical tasks to solve basic math problems that are connected with addition, subtraction, division and multiplication). Students use coins in different colours, each colour representing one number that students need to remember in order to solve the given problems. They could find more different strategies to solve one specific problem. In the music part, students listen to the given rhythm. They use figures of monkeys in the same colours as the coins in the math part and try to connect each monkey colour with the sound the instructor gives to them. When students remember and connect the colour with the sound, they must listen to the rhythm and put specific and correct monkey in a right place in the created rectangle. They count rhythmic 
pulse on the rectangle (one and two and three and four - number the strings and the centre of the sides of the rectangles) all the time and decide where to put each given monkeys (sound). Instructors change the numbers of sounds, monkeys and rhythm each time.

Results of the empirical research presented the answers of children aged from eight to twelve years to the claims placed in the assessment scale, referring to attitudes that indicate the extent to which the mathematical-music game Musical Monkeys contributed to the development of the specific social and emotional skills of children.

The sample of the study subjects is shown in table format (Table 1) indicating the entire sample, as well as the sample per school and actual play workshop. This paper presents and compares answers provided by the pupils, taking into consideration the variable value of the student gender, in relation to the gender of the participants, as well as differences and similarities in children's attitudes relative to their gender. Therefore, Table 2 presents an indication of the sample of study subjects relative to the gender of the tested students.

Table 1 The sample of the study subjects and the total answers provided by the study

\begin{tabular}{|l|l|l|l|l|l|l|}
\hline \multicolumn{2}{|c|}{ Workshoop } & \multicolumn{2}{c|}{ The first workshoop } & \multicolumn{2}{c|}{$\begin{array}{l}\text { The second } \\
\text { workshoop }\end{array}$} & \multicolumn{2}{c|}{ All answers } \\
\hline $\begin{array}{l}\text { Primary school } \\
\text { „Kreativno pero" }\end{array}$ & $F$ & $\%$ & $f$ & $\%$ & $f$ & $\%$ \\
\hline Third grade & 18 & 32,72 & 18 & 36.00 & 36 & 34,28 \\
\hline Fourth grade & 21 & 38,18 & 16 & 32.00 & 37 & 35,23 \\
\hline Fift grade & 16 & 29,09 & 16 & 32.00 & 32 & 30,47 \\
\hline All respondants & 55 & $100 \%$ & 50 & $100 \%$ & 105 & $100 \%$ \\
\hline $\begin{array}{l}\text { Primary school } \\
\text { „Ruđer Bošković” }\end{array}$ & $F$ & $\%$ & $f$ & $\%$ & $f$ & $\%$ \\
\hline Third grade & 13 & 20.00 & 13 & 22,80 & 26 & 21,31 \\
\hline Fourth grade & 15 & 23.07 & 15 & 26,31 & 30 & 24,59 \\
\hline Fifth grade & 18 & 27.69 & 15 & 26,31 & 33 & 27,04 \\
\hline Sixth grade & 19 & 29,63 & 14 & 24,56 & 33 & 27,04 \\
\hline All respondants & 65 & $100 \%$ & 57 & $100 \%$ & 122 & $100 \%$ \\
\hline
\end{tabular}


Table 2 The sample of the study subjects and the total answers provided by the study, relative to the gender of the subjects

\begin{tabular}{|l|l|l|l|l|l|l|}
\hline \multicolumn{2}{|l|}{$\begin{array}{l}\text { Workshoop } \\
\text { Gender }\end{array}$} & $\begin{array}{l}\text { The first } \\
\text { workshoop } \\
\text { (Respondants) }\end{array}$ & \multicolumn{2}{l|l}{$\begin{array}{l}\text { The second } \\
\text { workshoop } \\
\text { (Respondants) }\end{array}$} & \multicolumn{2}{l}{$\begin{array}{l}\text { Both workshops } \\
\text { (Answers of the } \\
\text { respondants) }\end{array}$} \\
\hline \multirow{2}{*}{ Male } & $f$ & $\%$ & $f$ & $\%$ & $f$ & $\%$ \\
\cline { 2 - 8 } & 58 & 53,21 & 51 & 46,78 & 109 & 48,01 \\
\hline \multirow{2}{*}{ Female } & $f$ & $\%$ & $f$ & $\%$ & $f$ & $\%$ \\
\cline { 2 - 8 } & 62 & 52,54 & 56 & 47,45 & 118 & 51,98 \\
\hline \multirow{2}{*}{ All answers } & $f$ & $\%$ & $f$ & $\%$ & $f$ & 100.00 \\
\cline { 2 - 8 } & 120 & 100.00 & 107 & 100.00 & 227 & $\%$ \\
\hline
\end{tabular}

The descriptive method was chosen for the presentation of the empirical study. Within the descriptive method, the observation technique was used, while the observation protocol was implemented as the measuring instrument. Apart from the observation technique, scaling technique was also used for the more thorough collection of data, while the estimate scale was used for as the measuring instrument. The study subjects were filling in the scale, marking their attitude within three-level grade - choosing to 'disagree', 'partly agree' or 'fully agree' with the aims for determining the opinion and estimate of the study subjects regarding whether and to what extent the implemented mathematical and musical play contributes to the following:

- collaboration and joining in in activities with other children,

- appreciation of opinions and attitudes of other children,

- team work,

- $\quad$ encouraging competitive spirit,

- interaction in communication with other participants,

- encouraging curiosity and desire for partaking,

- $\quad$ respecting the rules of the game,

- $\quad$ satisfaction of participating in the play.

The extent to which the actual play contributed to collaboration among the children in solving the set mathematical and/or musical tasks is indicated by the answers provided by the participants, revealing that which reveal that following the first and the second workshops, there was a significantly high percentage of answers confirming that the play fully encourages collaboration and joint work. The ensuing analysis reveals that this percentage constitutes $82.37 \%$ of the total answers provided, which is significantly more in comparison with $4.40 \%$ of answers claiming 'disagreement' with the statement that the play contributes to collaboration and joint work. From the aspect of the subjects' gender, the results show an equal distribution of answers among boys and girls, with as many as $82.57 \%$ boys' and $82.20 \%$ girls' answers supporting the statement that the actual 
game encouraged them to engage in collaboration and joint efforts in solving the assigned tasks. A larger proportion of the girls' answers (5.93\%) compared to the boys' $(2.75 \%)$ supporting the 'disagree' option in the survey indicate non-supportiveness of the play to collaboration and joint work with other children. However, the above percentages are insignificant in comparison with the percentages within the 'fully agree' option of the evaluation survey.

The graph representations of the frequencies were formed in accordance with the presented percentages of answers and they mostly confirm the statement of 'full' collaboration in the course of the play, thereby contributing to the confirmation of the defined stance and also confirming the supposition that the actual game will encourage collaboration among children owing to its concept, the content and the method of implementation (Graph 1).

I comunicated and collaborated with other students while playing the game

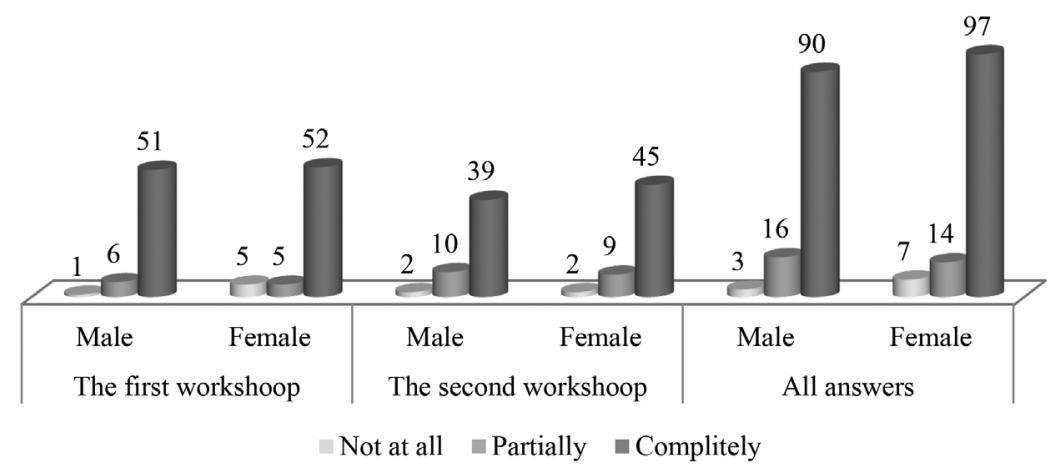

Graph 1 I collaborated and cooperated with other students while plying the game

The extent to which the children listened to and appreciated the other children's opinions during the mathematical and musical play Musical Monkeys, and also the extent of the game's contribution to this process is indicated primarily by the answers provided by the entire body of the study subjects. A mere $3.08 \%$ of the total answers indicated 'disagreement' with the statement that the play contributed to mutual appreciation and acceptance, whereas as many as $77.97 \%$ of the total answers indicated 'full agreement' with the statement that the play contributes to encouragement of mutual appreciation and acceptance. The answers within the category 'partly agree' comprise $18.95 \%$ of the total answers. The extremely low percentage of answers indicating that the study subjects failed to appreciate and accept opinions of the other children during the game, point to the opposite conclusion and significantly supports the stance that the game encourages social and emotional development of children. 
Analysing the answers from the aspect of the study subjects' gender, it has been established that $79.82 \%$ of male and $76.27 \%$ of female study subjects confirm the assertion that the game encourages appreciation and acceptance of other chiledren's opinion. Disagreement with this statement was expressed by $2.75 \%$ of the boys and 3.39\% of the girls, which indicates that the stated claim was insignificantly impacted by the subjects' gender. Comparing the overall results and the results obtained from the study subjects taking into consideration their gender, it can be observed that these two categories of answers are aligned to a high extent. The percentage values are shown in frequency arrangement in Graph 2, illustrating the responses of the boys and the girls at each game realization. The graph illustratively confirms that the play encouraged the socio-emotional development of the children through participation in the offered activities.

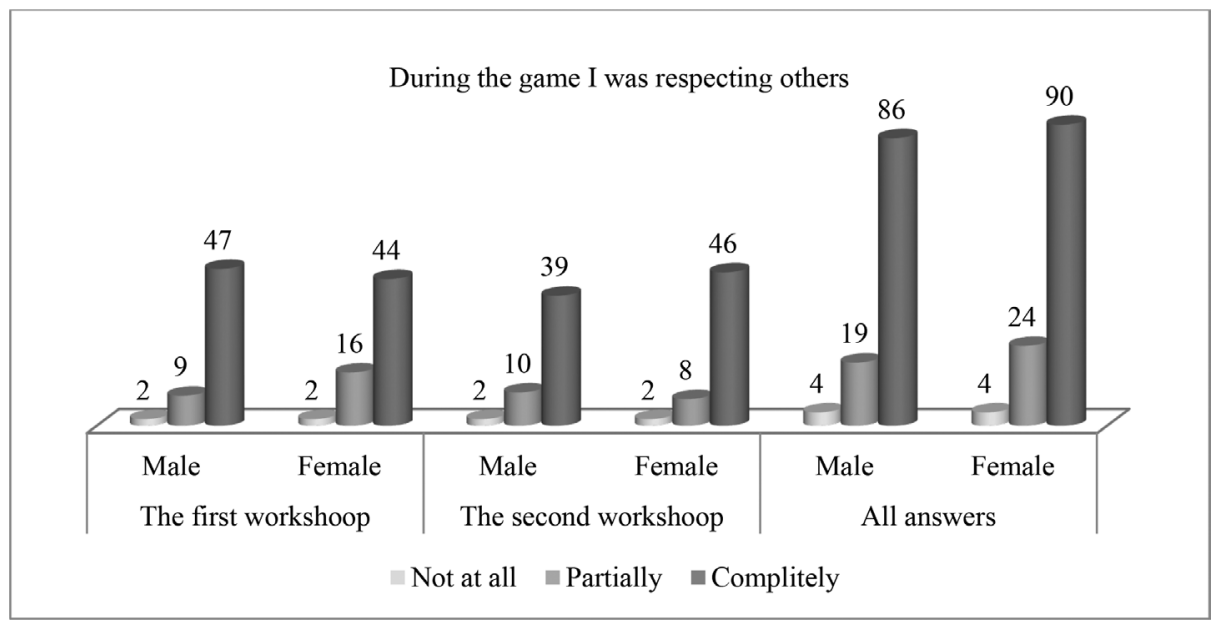

Graph 2 During the game I was respecting others

The very concept of the game implies organisation of teams of participants, thereby encouraging team work. The extent to which the children actually worked as a team to solve the set tasks is shown by the obtained and checked responses. Out of the total number of the responses obtained from all of the study subjects, there were $85.03 \%$ indicating full agreement with the statement that the game encourages team work, contributing to confirmation of this statement. Taking into consideration the variable of the study subjects' gender, the results are approximately the same. The percentage presentation of the answers provided by the boys confirming the statement amount to around $84.40 \%$ of the total number of answers, compared to $85.60 \%$ answers of the same category given by the girls. Based on the presented statistics, it can be concluded that play encourages and contributes to team work, regardless of the study subjects' gender, thereby fostering one of the 
key social skills of our time. Responses presented in the frequency pattern illustrate the obtained results and point to the ratio of the obtained answers (Graph 3).

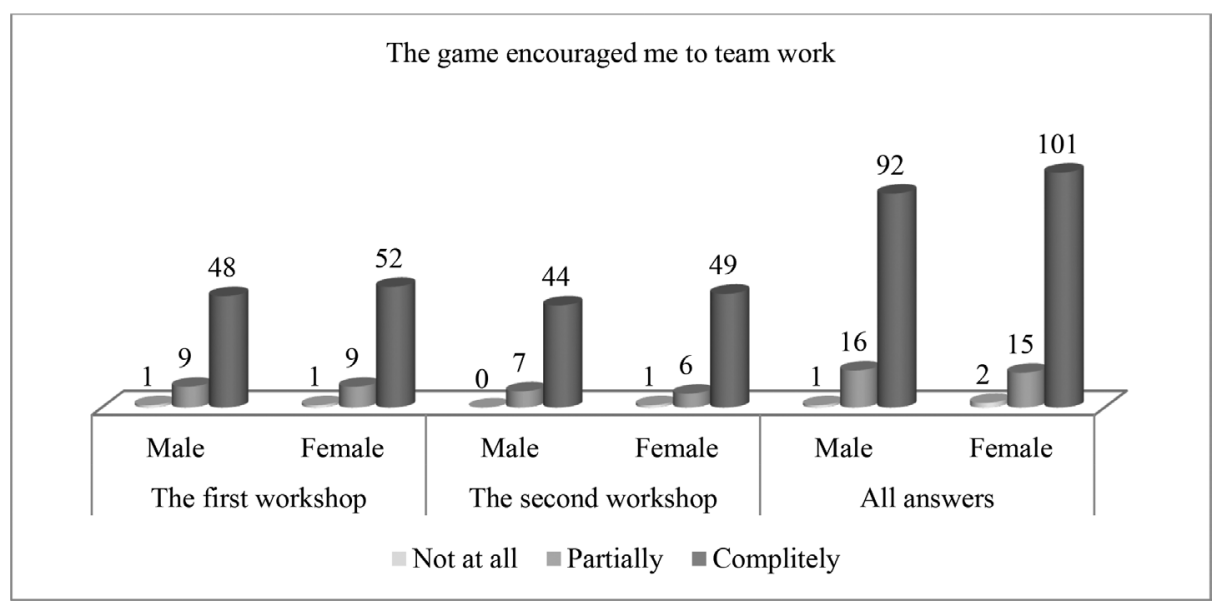

Graph 3 The game encouraged me to team work

Analysing the graph, it is evident that regardless of the realization of the game, for both gender categories the dominant frequencies are the ones matching the answer 'fully agree' with statement that the play Musical Monkeys encouraged team work.

The mathematical and musical game Musical Monkeys was realized during the research as a competition game. The results obtained after analysing the answers are fully indicative of the fact that the study subjects predominantly expressed a positive attitude regarding the encouragement of the competition spirit by the actual game. The majority of the study subjects or $72.68 \%$ of them stated that the game fully encouraged the competition spirit, with $18.94 \%$ stating that it was partly supportive of the competitive spirit, and only $8.37 \%$ stating that it did not encourage the competition spirit 'at all'. Analysed from the aspect of the gender variable, the answers produce the following results: a larger percentage of the male subjects $(77.06 \%)$ fully agreed with the statement that the game encourages competitive spirit, compared to the same category of answers within the female sub-category (68.64\%). Considering that the percentage values of the responses of both genders of study subjects given for the 'fully agree' option of evaluation are in excess of $65.00 \%$ of the total number of answers, it can be concluded that the claimed encouragement of the competition spirit can be confirmed. This statement is additionally confirmed by the $22.04 \%$ answers in the category of 'partly agree', and only $9.23 \%$ of the answers opposing this statement. Regardless of the difference revealed in the respective percentages for boys' and girls' responses, the frequency graph confirms that the study subjects of both genders, irrespective of 
the actual realization of the game, confirmed the statement that the play contributes to encouragement of the competition spirit (Graph 4).

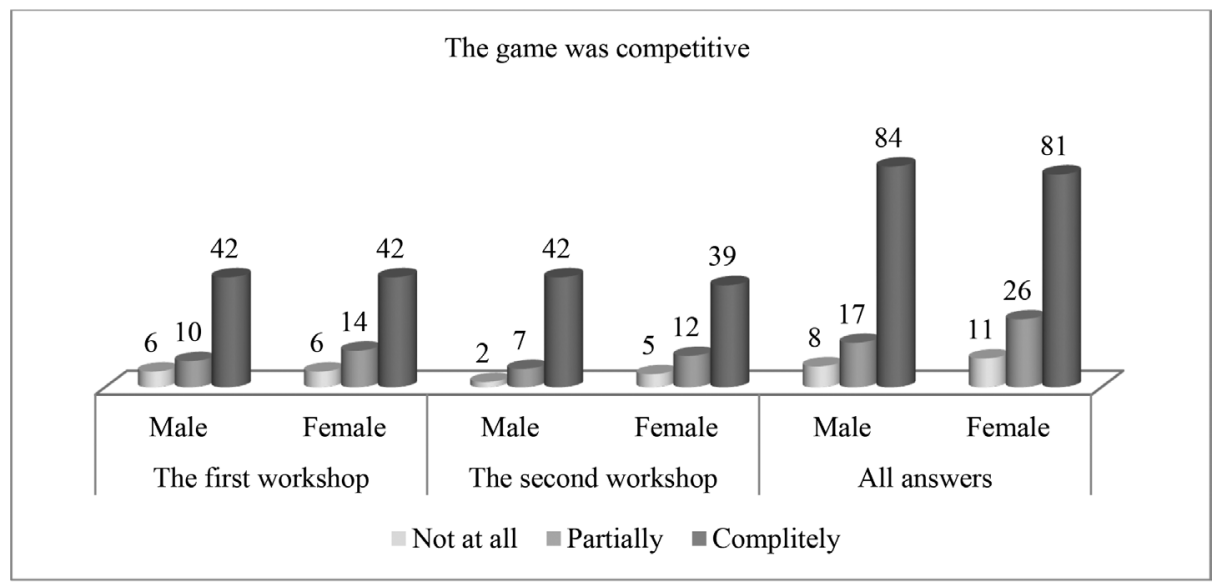

Graph 4 The game was competitive

The research included the analysis of the responses to consideration whether and to what extent play encourages constructive communication among the children, i.e. among the participants in the game. According to the obtained results, the communication among the participants was at a very high level, considering that $84.14 \%$ of the study subjects' responses indicated that during the play there was a full incentive to engage in constructive communication in order to reach the answers and jointly solve the set tasks. Based on this it is possible to draw a general conclusion that the social skill of constructive communication is to a high extent encouraged by play, i.e. that play enabled children to develop communication skills. The same attitude is reflected by the answers provided by boys and girls alike (represented by $87.16 \%$ of boys' and $81.37 \%$ girls' answers). Graph 5 presents graphic illustration of frequencies of the responses provided by the study subjects of both genders. 
During the game I was comunicating with other students with the aim to find common solution for the given problems

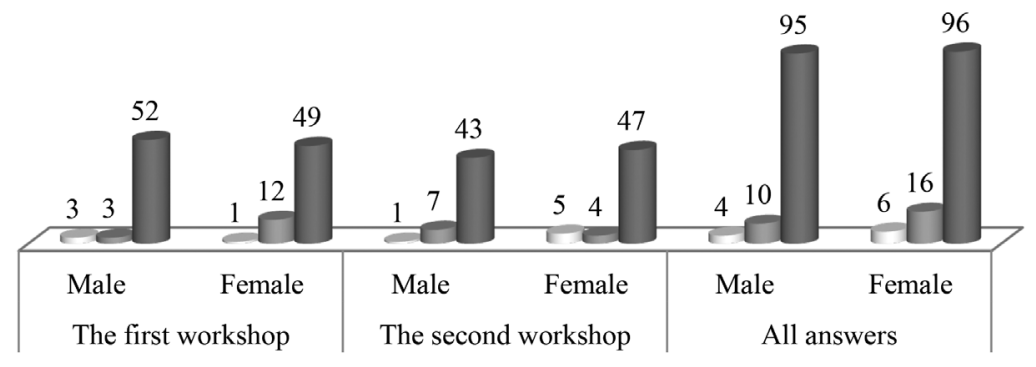

Not at all $\square$ Partially $\backsim$ Complitely

Graph 5 During the game I was communicating with other students with the aim to find common solution for the given problems - answers to the gender

When a teaching or other type of activity, a workshop or a game involving children provokes curiosity and generates the wish for participation, there is no doubt that we are dealing with encouragement of emotional skills and emotional development of children through play and acquisition of certain contents. One of the statements included in the research aimed at revealing the extent to which the actual game encouraged the participants' desire to partake in it.

An overview form the aspect of the total answers provided by the participants, more than eighty percent of the answers indicated that the actual game 'fully' encouraged children's curiosity and desire for participation. When this is expanded by adding the percentage of responses claiming 'partial' agreement with the statement, it becomes evident that over $90.00 \%$ of the total answers provided by the study subjects confirm the statement that to a higher or lesser degree the actual game encourages curiosity and desire for participation, based on which it can be concluded that it encourages social and emotional development of children. The analysis of the responses from the aspect of the study subjects' gender reveals an insignificantly larger number of the male subjects' responses $(84.40 \%)$ compared to the responses provide by the female subjects $(76.27 \%)$ expressing agreement with the statement that the game encouraged curiosity and generated desire among the children for participation in the mathematical and musical game. A presentation of the obtained answers grouped according to the gender of the study subjects, expressed as frequencies are shown in the graph (Graph 6). The graph illustrates the conclusion that regardless of the subjects' gender and the sequence of the implementation of the mathematical and musical play, the dominant position is taken by the frequencies reflecting the 'fully agree' response to the statements, thereby 
confirming that the actual mathematical and musical game encouraged curiosity and desire to participate in study subjects of both genders.

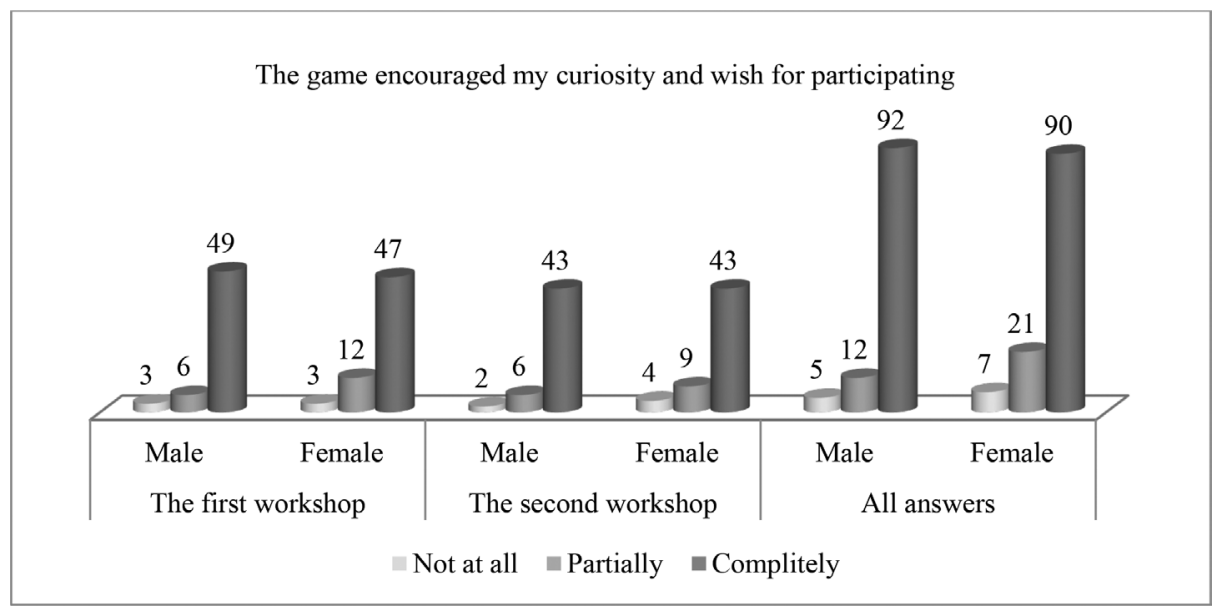

Graph 6 The game encouraged my curiosity and wish for participating

Respecting the rules of the game is a key moment in social and emotional development of children. The analysis of the responses to the statement evaluating the respect for the rules of the game leads to the interesting conclusion that over $90.00 \%$ of the study subjects stated that they fully respected the rules of the Musical Monkeys game. At the same time, a markedly low percentage of responses $(1.32 \%)$ stated that the participants did not respect the defined rules of the game 'at all', while $5.37 \%$ of the responses fall into the category of 'partial' compliance with the rules of the game.

Irrespectively of the study subjects' gender, over $90.00 \%$ of the responses ( $93.58 \%$ of the male subjects and $92.37 \%$ of the female subjects) confirmed the attitude of respecting the rules of the game. It is interesting to observe that the percentage of answers within the 'fully agree' option ('I fully respected the rules of the game') tends to be higher among the male subjects than among the female ones. The frequency and the graphic illustration of the answers provided by the subjects of both genders are given in Graph 7. The illustratively presented results confirm the claim that the game contributed to a high extent to children's respect of the rules, thereby contributing to the development of another vital social skill. 
During the game I was respecting rules of the game

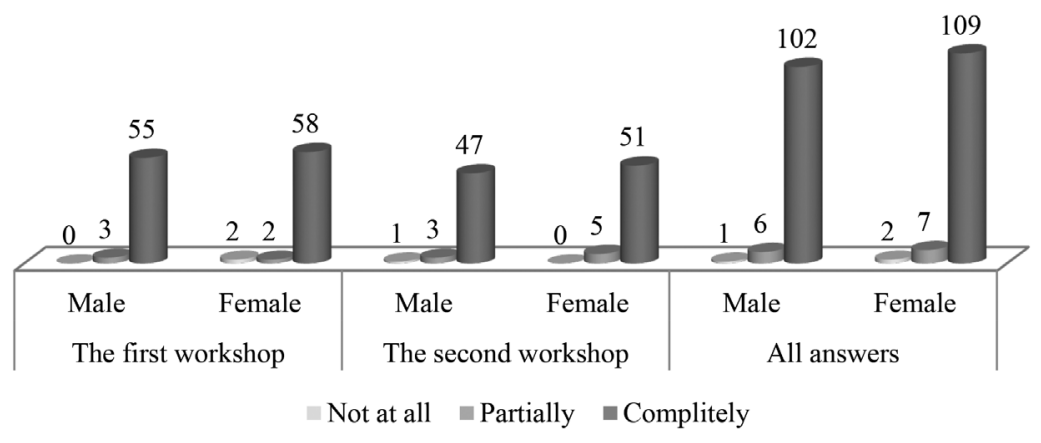

Graph 7 During the game I was respecting rules of the game

The extent to which the mathematical and musical game titled Musical Monkeys contributed to the children's enjoyment during its implementation and their participation in it, is shown by the analysis of the responses to the statement demanding an answer along the scale 'I enjoyed participating in the game'.

The calculation of the percentages for the obtained answers reveals general agreement with the above statement, considering that over $85.00 \%$ of the answers stated full agreement with the statement that the participation in the game was a pleasurable experience $(86.78 \%)$. In addition, there were $9.70 \%$ of the answers stating partial agreement with the statement, and only $3.52 \%$ stating the participants' dissatisfaction with the participation in the game.

The analysis of the responses from the aspect of the study subjects' gender did not establish a significant difference in the percentages of answers grouped into two categories of 'partly' and 'fully', with $89.91 \%$ of the boys choosing the 'fully agree' option, compared to $83.90 \%$ of the girls choosing the same answer. The option 'partly agree' was chosen by $9.17 \%$ of the boys, compared to $10.17 \%$ of the girls' answers in this category. However, difference in the percentages of responses is visible in the 'not at all agree' category of the responses, with only $0.92 \%$ of the boys choosing this option, compared to a significantly larger percentage of girls' answers in this category, $5.93 \%$. The frequency-based graphic presentation of the obtained percentages is shown in Graph 8, with a clear confirmation of the claim that the game encourages to a high degree development of emotional skills in children, their enjoyment during learning, pleasure, curiosity and the similar elements. 


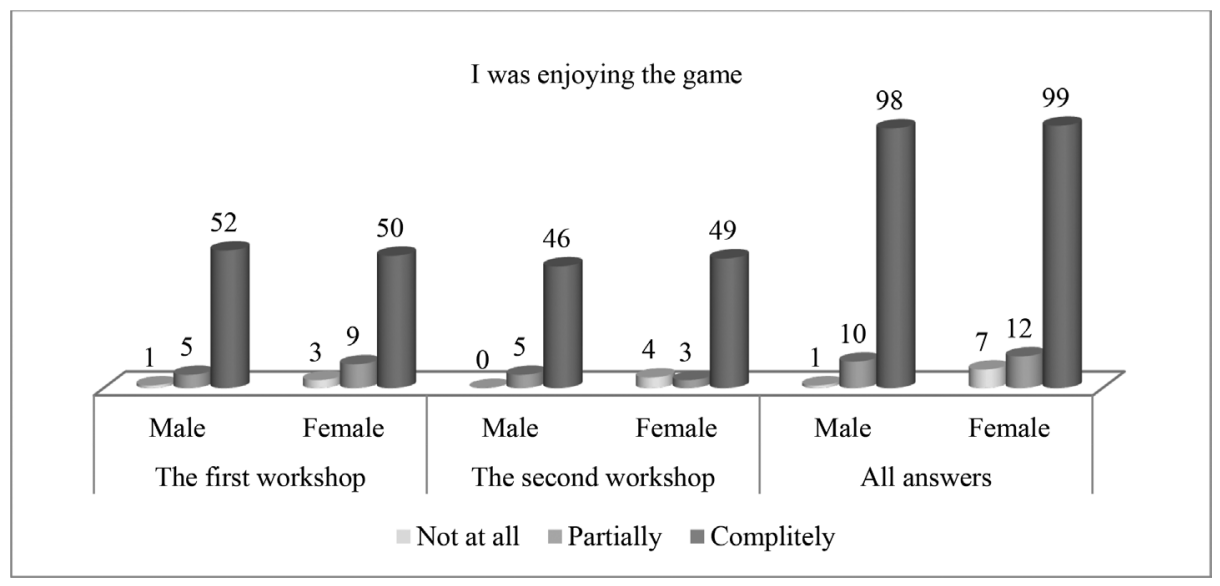

Graph 8 I was enjoying the game

\section{CONCLUSION}

Based on the facts presented thus far and the analysis of the obtained answers to the questions aimed to establish to what extent they actually realized mathematical and musical game encouraged the social and emotional development and development of social skills in children, it is possible to conclude that for each of the questions within this category of statements, the largest number of answers fall into the categories of 'fully agree' and 'partly agree', compared to the option 'not agree at all' on the formed scale of assessment.

Based on the analysis of the statements aimed to establish a contribution made by the game to the development of social skills of the children/study subjects through the actually realized mathematical and musical game Musical Monkeys, as well as the contribution of the game to the socio-emotional development of the children, it can be concluded that the realized game contributes to high extent to encouragement of collaboration and acceptance, as well as the encouragement of tolerance, mutual appreciation and consideration of other children's opinions in the course of solving the set mathematical and/or musical tasks, team work and encouragement of the team spirit, enthusiasm and curiosity to partake in the game, as well as respect for its rules and other social and emotional skills bearing crucial importance to the development of children. The obtained results indicate that the interdisciplinary game contributed to a higher level of constructive communication among the students encouraging them to reach mutual agreements when finding solutions to given mathematical and musical problems. The Musical Monkeys game causes enthusiasm, excitement and enjoyment for children age 8 to 10 that tested giving us a solid basis for further research with older students with similar interdisciplinary games. In a wide area of the research done we also get 
very positive answers from teachers who participate in the research project. They portrait that the tested game motivates students to work, cooperate, communicate, think, organise their team work etc.

Children's responses also point out the expressed motivation and engagement during the game, the desire to continue the game, the desire for success, and greater focus, attention and concentration during the game. On the basis of the analysed results, it was concluded that the game at the highest level was motivational and that encouraged children to activity, engagement, cooperation, collaboration, enthusiasm, attention and concentration etc. The research done is the starting point for devising other interactive and dynamic mathematical and musical games, with a highly significant application in activities involving children at school at outside school, encouraging a modern approach to tuition and development of a complete personality, while this work also showed the development of certain social and emotional skills of the children.

\section{REFERENCES}

1. Athey, M. \& Hotchkiss, G. (1978). Music Learning Grows with Games, Music Educators Journal, 64(8), 48-51.

2. Barr, M. (2017). Video games can develop graduate skills in higher education students: A randomized trial. Computer \& Education, 113, 86-97. https://doi.org/10.1016/j. compedu.2017.05.016

3. Dejic, M. \& Egeric, M. (2006). Methodology of teaching mathematics. Faculty of Teacher Education. (Original reference: Дејић, М. и Егерић, М. (2006). Методика наставе математике. Учитељски факултет).

4. Denmark, T, Kepner, H., et. al. (1980). Basic Skills in Mathematics: A Survey, Journal for Research in Mathematics Education, 11(2), 104-123.

5. Ivic, I. (1997). Active learning. Institute of Psychology. (Original reference: Ивић, И. и сар. (1997). Активно учење. Институт за психологију).

6. Kamenov, E. (2009). Children's play. Institute for Textbooks. (Original reference: Kamenov, E. (2009): Dečja igra. Zavod za učbenike).

7. Karic, J. (2015). Mathematical Games. Beogradska defektološka škola, 21(3), 8189. (Original reference: Karić, J. (2015). Matematičke igre. Beogradska defektološka škola, 21(3), 81-89).

8. Levy, J. (1978). Play behaviour. John Wiley \& Sons.

9. Plummer, D. (2008). Social Skills Games for Children. Jessica Kingsley Publishers.

10. Rados, K. (2010). Psychology of music. Institute for Textbooks. (Original references: Radoš, K. (2010). Psihologija muzike. Zavod za udžbenike).

11. Song, A. Capraro, M. M. \& Tillman, D. (2013). Elementary Teachers Integrate Music Activities into Regular Mathematics Lessons: Effects on students' Mathematical Abilities. Journal for Learning through the Arts, 9(1), 1-19. https://doi.org/10.21977/ D99112867

12. Tasevska, A. (2005). Game activity as a method concept in the initial educational cycle (Doctoral dissertation). Faculty of Philosophy. (Original reference: Тасевска 
А. (2005). Игровна активност као методски концепт во првот образовен циклус (Докторска дисертација). Филозофски факултет).

13. Trebešanin, Z. (2008). Dictionary of Psychology. Pillars of Culture. (Original references: Требјешанин, Ж. (2008). Речник психологије. Стубови културе).

14. Whitebread, D. (2012). The importance of play. University of Cambridge. 